\title{
Pediatric Hospitalists: Training, Current Practice, and Career Goals
}

\author{
Gary L. Freed, MD, MPH ${ }^{1,2}$ \\ Kelly M. Dunham, MPP ${ }^{1,2}$ \\ Research Advisory Committee of the \\ American Board of Pediatrics ${ }^{3}$ \\ ${ }^{1}$ Child Health Evaluation and Research (CHEAR) \\ Unit, University of Michigan, Ann Arbor, Michigan. \\ ${ }^{2}$ Division of General Pediatrics, University of \\ Michigan, Ann Arbor, Michigan. \\ ${ }^{3}$ American Board of Pediatrics, Chapel Hill, North \\ Carolina.
}

OBJECTIVE: To determine the range and frequency of experiences, clinical and nonclinical roles, training, work expectations, and career plans of practicing pediatric hospitalists.

DESIGN: Mail survey study of a national sample of 530 pediatric hospitalists of whom $67 \%(\mathrm{~N}=338)$ were from teaching hospitals, $71 \%(\mathrm{~N}=374)$ were from children's hospitals, $43 \%(\mathrm{~N}=230)$ were from freestanding children's hospitals, and $69 \%(\mathrm{~N}=354)$ were from hospitals with $\geq 250$ beds.

RESULTS: The response rate was $84 \%$. The majority $(54 \% ; \mathrm{N}=211$ ) had been practicing as hospitalists for at least 3 years. Most reported that the pediatric inpatient unit (94\%) and inpatient consultation service $(51 \%)$ were a part of their regular clinical assignment. Most did not provide service in the normal newborn nursery $(58 \%)$, subspecialty inpatient service $(52 \%)$, transports $(85 \%)$, outpatient clinics $(66 \%)$, or as part of an emergency response team (53\%). Many participated in quality improvement (QI) initiatives (84\%) and practice guideline development (81\%).

CONCLUSIONS: This study provides the most comprehensive information available regarding the clinical and nonclinical roles, training, work expectations, and career plans of pediatric hospitalists. However, the field is currently a moving target; there is significant flux in the hospitalist workforce and variation in the roles of these professionals in their clinical and nonclinical work environment. Journal of Hospital Medicine 2009;4:179-186. () 2009 Society of Hospital Medicine.

KEYWORDS: academic appointment, career trajectory, clinical practice, employment characteristics, job satisfaction.

$\mathbf{T}$ here has been marked recent growth in the employment and utilization of both pediatric and adult hospitalists. Recent data demonstrate that approximately $25 \%$ of current pediatric hospitalist programs are less than 2 years old. ${ }^{1}$ Some have posited that this growth is due to increasing pressure from the public and payors to deliver cost-effective and high-quality care. ${ }^{2}$ However, little is known about the mechanisms by which those who deliver care in this framework are trained, nor the scope of clinical practice they provide. $^{3-7}$ One study has shown that among those who direct pediatric hospitalist services there is a great degree of variability in the description of the roles, work patterns, and employment characteristics of hospitalists. ${ }^{1}$ That study provided only 1 perspective on the roles and career trajectories of those in the field. To better understand both the range and frequency of experiences, clinical and nonclinical roles, training, work expectations, and career plans, we conducted a national survey study of practicing pediatric hospitalists. 


\section{METHODS \\ Sample}

We identified all 761 hospitals in the American Hospital Association (AHA)'s 2005 Annual Survey of Hospitals that reported to have both a hospitalist service (adult and/or pediatric) and pediatric beds. From these 761 hospitals, we selected a random sample of 213 , stratified by:

- Council of Teaching Hospital (COTH) designation

- National Association of Children's Hospitals \& Related Institutions (NACHRI) membership

- Freestanding children's hospitals

- Metropolitan Statistical Area (MSA) (urban versus rural location)

- Hospital size (small: $<250$ total beds versus large: $\geq 250$ total beds)

Some hospitals are included in more than 1 category. Thus, there is some overlap of hospitals in the analysis. Of these 213 hospitals, 97 were removed from the sample because they did not have at least 1 pediatric hospitalist. In a separate study, we surveyed hospitalist program directors at 112 of the remaining 116 hospitals from June through September 2006. These results have been published. ${ }^{1}$

Pediatric hospitalist program directors at these 112 participating hospitals were asked to provide the names of all practicing pediatric hospitalists in their respective programs. Ninety-five of these program directors provided a list of hospitalists at their institutions, representing $85 \%$ of the hospitals in our previous study. A total of 530 practicing pediatric hospitalists were identified to us in this manner. Of these 530 hospitalists, $67 \%(\mathrm{~N}=338)$ were from teaching hospitals, $71 \%(\mathrm{~N}=374)$ were from children's hospitals, $43 \%(\mathrm{~N}=230)$ were from freestanding children's hospitals, and $69 \%(\mathrm{~N}$ $=354$ ) were from hospitals with $\geq 250$ beds. These are not mutually exclusive categories.

\section{Survey Instrument}

We developed a structured questionnaire to be administered by mail. The survey contained 25 items and was designed to be completed in 10 minutes or less. The survey focused on exploring the characteristics of hospitalist clinical and nonclinical practice, service schedule, training, and career goals. The questionnaire was comprised of a mixture of fixed-choice, Likert-scale, and openended questions.

\section{Questionnaire Administration}

In October 2006, the first mailing of questionnaires was sent via priority mail. The survey packet contained a personalized cover letter signed by the principal investigator (G.L.F.), the instrument, a business reply mail envelope, and a $\$ 5$ bill as an incentive. Two additional mailings were sent to nonrespondents in November 2006 and January 2007.

\section{Data Analysis}

First, frequency distributions were calculated for all survey items. Next, comparisons were made between respondents indicating they held an academic appointment and those who did not. For the purposes of this analysis, academic pediatric hospitalists were defined as those respondents holding a full-time or part-time academic appointment. Nonacademic pediatric hospitalists were defined as respondents holding an adjunct or volunteer faculty position, or no academic appointment. Finally, chi-square statistics were used to compare pediatric hospitalist responses by hospital demographics such as teaching status, children's hospital status, NACHRI freestanding hospital designation, and hospital bed size.

The study was approved by the University of Michigan Medical Institutional Review Board.

\section{RESULTS \\ Response Rate}

Of the initial 530 survey packets mailed, 18 were returned as undeliverable by the postal service and 431 physicians returned the survey. This yielded an overall response rate of $84 \%$. Of the 431 respondents, 40 physicians were ineligible because they no longer provided inpatient care to children or did not consider themselves to be hospitalists. Thus, the final sample for analysis was 391 .

\section{Hospitalist Employment Characteristics Demographics of Hospital Worksite}

Of the 391 respondents, $61 \%(\mathrm{~N}=237)$ were from teaching hospitals, $73 \%(\mathrm{~N}=287)$ from children's hospitals, $47 \%(\mathrm{~N}=182)$ from freestanding children's hospitals, and $66 \%(\mathrm{~N}=258)$ from hospitals with more than 250 beds.

\section{Physician Demographics}

The mean age of respondents was 39 years and $59 \%$ were female. The majority were employed by 
TABLE 1

Length of Time Practicing as a Hospitalist

\begin{tabular}{lc}
\hline Length of Time as Hospitalist & \% (N) \\
\hline$\leq 12$ months & $13(51)$ \\
$13-24$ months & $18(71)$ \\
$25-36$ months & $14(56)$ \\
$37-60$ months & $17(67)$ \\
$>61$ months & $37(144)$ \\
\hline
\end{tabular}

NOTE: $\mathrm{N}=389$; values given are percent and number of hospitalists.

a hospital or health system (56\%), $20 \%$ were employed by a university, and $4 \%$ were employed by both. Eight percent reported employment by a general physician medical group, $7 \%$ were employed by a hospitalist-only group, and $4 \%$ reported other sources of employment. Half of respondents $(\mathrm{N}=196)$ reported holding a fulltime $(40 \%)$ or part-time $(10 \%)$ academic appointment. Approximately half the respondents $(\mathrm{N}=194)$ were considered nonacademic hospitalists.

More than half of respondents $(54 \% ; \mathrm{N}=211)$ had been practicing as hospitalists for at least 3 years. Reported time as a practicing hospitalist ranged from $<1$ year to 26 years, while the average length of time was 63 months (Table 1). These figures may be skewed because those hospitalists with higher turnover rates might have left their position during the period of time from when they were selected into the sample until the time of survey administration.

\section{Clinical Practice}

Most respondents reported that the pediatric inpatient unit (94\%) and inpatient consultation service $(51 \%)$ were a part of their regular clinical assignment (Table 2). A majority did not provide service in the normal newborn nursery (58\%), subspecialty inpatient service (52\%), pediatric intensive care unit (ICU) (70\%), neonatal ICU (77\%), transports (85\%), outpatient clinics $(66 \%)$, or as part of an emergency response team (53\%).

With regard to procedures, many (53\%) respondents reported that they routinely perform or supervise lumbar punctures. Several services are never performed or never supervised by the majority of pediatric hospitalists, including infusion services (57\%), peripherally inserted central catheter (PICC) placement $(76 \%)$, central line placement (67\%), and circumcision (85\%).
TABLE 2

Hospitalist Service in Specific Clinical Settings

\begin{tabular}{lllc}
\hline & $\begin{array}{l}\text { Part of Regular } \\
\text { Clinical } \\
\text { Assignment \% (N) }\end{array}$ & $\begin{array}{l}\text { Occasionally } \\
\text { \% (N) }\end{array}$ & $\begin{array}{l}\text { Never } \\
\text { \% (N) }\end{array}$ \\
\hline Pediatric inpatient unit & $94(368)$ & $3(13)$ & $2(9)$ \\
Inpatient consultation service & $51(199)$ & $40(155)$ & $9(35)$ \\
Normal newborn nursery & $29(110)$ & $13(50)$ & $58(223)$ \\
Emergency department & $25(95)$ & $28(108)$ & $47(178)$ \\
Subspecialty inpatient service & $25(92)$ & $23(86)$ & $52(196)$ \\
Emergency response team & $23(87)$ & $24(91)$ & $53(201)$ \\
Outpatient/outreach clinics & $18(68)$ & $16(61)$ & $66(253)$ \\
Pediatric ICU & $14(54)$ & $16(59)$ & $70(268)$ \\
Neonatal ICU & $12(44)$ & $11(42)$ & $77(294)$ \\
Transports & $9(33)$ & $6(23)$ & $85(319)$ \\
\hline
\end{tabular}

NOTE: N = 390; values given are the percent and number of hospitalists responding "yes" to providing care in a specific setting.

Abbreviation: ICU, intensive care unit.

\section{Professional Roles and Parameters}

Respondents reported that they participate in a variety of nonclinical activities. Ninety-four percent of hospitalists were involved in education, and $45 \%$ reported having a leadership role in that area. The majority of respondents participated in quality improvement (QI) initiatives (84\%) and practice guideline development $(81 \%)$, with one-quarter of hospitalists reporting a leadership role in each of these activities. Slightly more than half of respondents reported involvement in hospital administration (52\%) and utilization review (55\%) (Table 3).

On average, hospitalists reported spending $61 \%$ of their time providing inpatient care (excluding clinical teaching) and $16 \%$ of their time providing clinical teaching or supervising residents. More than one-third of respondents (38\%) spent more than $75 \%$ of their time providing direct inpatient care. Research (3\%), administrative duties (8\%), and nonclinical teaching (3\%) were reported to be a small part of hospitalist professional time.

\section{Pediatric Hospitalist Service Schedule}

The majority of respondents reported that their assigned clinical schedule was a combination of shift and call (61\%).

When on service, over half of responding pediatric hospitalists $(58 \%)$ reported that they spend 40 to 60 hours onsite per week. Less than one-fifth of respondents (19\%) reported that they provide $<40$ hours of onsite coverage when on service. Most (97\%) provide some type of night coverage, 
TABLE 3

Hospitalist Role in Nonclinical Settings

\begin{tabular}{|c|c|c|c|}
\hline & \multicolumn{2}{|c|}{ Participation } & \multirow[b]{2}{*}{$\begin{array}{l}\text { No Involvement } \\
\% \text { (N) }\end{array}$} \\
\hline & $\begin{array}{l}\text { Participation of } \\
\text { Any Type \% (N) }\end{array}$ & $\begin{array}{l}\text { Leadership } \\
\text { Role \% (N) }\end{array}$ & \\
\hline Education (students, house staff) & $94(368)$ & $45(177)$ & $6(22)$ \\
\hline Quality improvement initiatives & $84(330)$ & $25(99)$ & $16(61)$ \\
\hline Practice guideline development & $81(313)$ & $26(101)$ & $19(74)$ \\
\hline Utilization review & $55(213)$ & $11(41)$ & $45(172)$ \\
\hline Hospital administration & $52(202)$ & $16(60)$ & $48(184)$ \\
\hline
\end{tabular}

NOTE: $N=391$; values given are the percent and number of hospitalists responding "yes."

including taking calls from home or providing onsite coverage.

\section{Hospitalist Training and Continuing Education}

Only 51 of the 391 respondents (13\%) had received some type of fellowship training, mostly in general pediatrics or the pediatric subspecialties. Only 5 respondents had received fellowship training in hospital medicine.

Fifty-eight percent of respondents reported that they had received no hospitalist-specific training. One-fifth reported that they received training through a workshop at a professional meeting, while fewer respondents had received hospitalist training though a continuing medical education (CME) course $(16 \%)$ or a mentoring program (17\%).

Respondents were asked to rate the adequacy of their respective training in preparing them for their work as hospitalists. The vast majority rated their training in general clinical skills $(94 \%)$ and communication $(85 \%)$ as fully adequate. However, respondents found their training for some of the nonclinical aspects of their positions to be deficient. Many respondents rated training for QI projects (38\%) and hospital administrative duties $(46 \%)$ as inadequate (Table 4$)$.

Survey respondents were asked to indicate the extent to which they agreed or disagreed with 3 statements regarding hospitalist training. The majority of respondents believed that hospitalists need training in QI methods (70\%). However, most pediatric hospitalists $(73 \%)$ did not believe that additional training beyond residency should be required. Only one-third (36\%) of respondents agreed that current CME offerings are adequate for their needs as a pediatric hospitalist.

\section{Career Goals and Expectations}

Respondents were asked to select 1 or more reasons why they became pediatric hospitalists. The top factors influencing respondents' decision to become a hospitalist were reported to be a preference for the inpatient setting (73\%), clinical variety $(72 \%)$, enjoyment of teaching in the inpatient setting (58\%), and a flexible schedule (52\%) (Table 5).

The majority $(85 \%)$ were satisfied with their position as a pediatric hospitalist, with $37 \%$ reporting that they were extremely satisfied. Over one-half $(61 \%)$ expected to remain a hospitalist for the duration of their career.

\section{RESULTS BY ACADEMIC STATUS}

Only significant differences between academic and nonacademic hospitalists are presented.

\section{Clinical Practice by Academic Status}

Nonacademic respondents were more likely than academic respondents to report regular service in the normal newborn nursery, pediatric ICU, neonatal ICU, transports, emergency department, and as part of an emergency response team. Academic respondents were more likely to report regular service in outpatient clinics. Nonacademic respondents were more likely than academic respondents to perform or supervise lumbar punctures, sedation services, PICC or central line insertions, and circumcisions (Table 6).

\section{Professional Roles and Parameters by Academic Status}

Responding academic pediatric hospitalists were twice as likely as nonacademic respondents to have a leadership role in the education of students and house staff and to hold a leadership position in hospital administration. The academic respondents were also more likely to report a leadership role in QI initiatives (Table 6).

\section{Clinical and Educational Activities by Academic Status}

Academic pediatric hospitalist respondents reported spending on average $52 \%$ of their time providing inpatient care (excluding teaching), in contrast to the nonacademic hospitalist respondents who reported $71 \%$ of their time was spent providing inpatient care $(P<0.0001)$. Academic respondents also reported that $19 \%$ of their time was spent providing inpatient teaching or supervising residents, compared to $12 \%$ of nonacademic respondents $(P<0.0001)$. Responding academic 
TABLE 4

Preferred Adequacy of Training in Preparation for Hospitalist Role

\begin{tabular}{|c|c|c|c|c|}
\hline & Fully Adequate $\%(\mathrm{~N})$ & Somewhat Adequate \% (N) & Not Adequate \% (N) & NA \% (N) \\
\hline General clinical skills & $94(367)$ & $5(21)$ & $0(0)$ & $0(1)$ \\
\hline Communication skills & $85(330)$ & $14(53)$ & $1(5)$ & $0(1)$ \\
\hline Coordination of care & $73(284)$ & $23(89)$ & $4(15)$ & 0 (1) \\
\hline Clinical procedure experience & $67(258)$ & $32(123)$ & $1(5)$ & $1(2)$ \\
\hline Teaching skills (resident and medical student teaching) & $64(248)$ & $31(120)$ & $3(13)$ & $2(8)$ \\
\hline Attending newborn deliveries & $60(233)$ & $18(70)$ & $4(14)$ & $19(72)$ \\
\hline Running resuscitation (codes) & $45(173)$ & $46(177)$ & $5(21)$ & $5(18)$ \\
\hline Quality improvement projects & $14(55)$ & $42(162)$ & $38(148)$ & $6(22)$ \\
\hline Hospital administrative duties & $10(37)$ & $37(144)$ & $46(177)$ & $8(31)$ \\
\hline
\end{tabular}

NOTE: $\mathrm{N}=389$; values given are the percent and number of hospitalists responding "yes."

Abbreviation: NA, not applicable.

TABLE 5

Factors Influencing Decision to Become a Hospitalist

\begin{tabular}{lc}
\hline Factor & \% (N) \\
\hline Prefer inpatient setting & $73(284)$ \\
Clinical variety & $72(281)$ \\
Enjoy teaching in inpatient setting & $58(225)$ \\
Flexible schedule & $52(202)$ \\
Defined hours & $41(161)$ \\
Attractive career opportunities & $21(80)$ \\
Salary & $18(70)$ \\
Unsure of long-term career direction & $13(51)$ \\
Other & $7(28)$ \\
Needed short-term employment & $4(15)$ \\
Only position available & $3(10)$ \\
\hline &
\end{tabular}

pediatric hospitalists reported spending a greater proportion of time participating in nonclinical teaching activities (5\% versus $2 \% ; P<0.0001)$, administrative duties ( $11 \%$ versus $5 \%$; $P<0.0001)$, and research (4\% versus $1 \%$; $P<0.0001)$ compared to the nonacademic respondents.

Nonacademic respondents were more likely than academic respondents to report no hospitalist-specific training (64\% versus 54\%; $P=0.0324$ ).

\section{RESULTS BY HOSPITAL CHARACTERISTICS}

For each hospital characteristic, only significant differences between dichotomized groups are presented.

\section{Children's Hospitals versus Other Hospitals Clinical Practice}

Pediatric hospitalist respondents practicing in NACHRI hospitals were more likely to report that
TABLE 6

Hospitalist Roles in Clinical and Nonclinical Settings: Academic versus Nonacademic Hospitalists

\begin{tabular}{|c|c|c|c|}
\hline & $\begin{array}{l}\text { Academic* } \\
(\mathrm{N}=196)\end{array}$ & $\begin{array}{l}\text { Nonacademic }{ }^{\dagger} \\
\text { (N = 194) }\end{array}$ & $P$ Value \\
\hline \multicolumn{4}{|l|}{ Regularly provides service } \\
\hline Normal newborn nursery & $16 \%$ & $42 \%$ & $<0.0001$ \\
\hline Pediatric ICU & $9 \%$ & $20 \%$ & 0.0065 \\
\hline Neonatal ICU & $4 \%$ & $20 \%$ & $<0.0001$ \\
\hline Transports & $3 \%$ & $15 \%$ & $<0.0001$ \\
\hline Emergency department & $16 \%$ & $34 \%$ & $<0.0001$ \\
\hline Emergency response team & $17 \%$ & $29 \%$ & $<0.0001$ \\
\hline Outpatient clinic & $23 \%$ & $13 \%$ & 0.0168 \\
\hline \multicolumn{4}{|l|}{ Performs or supervises procedures } \\
\hline Lumbar puncture & $84 \%$ & $92 \%$ & 0.0152 \\
\hline Sedation services & $50 \%$ & $64 \%$ & 0.0055 \\
\hline PICC insertion & $8 \%$ & $18 \%$ & 0.0031 \\
\hline Central line insertion & $11 \%$ & $23 \%$ & 0.0018 \\
\hline Circumcision & $5 \%$ & $16 \%$ & 0.0002 \\
\hline \multicolumn{4}{|l|}{ Holds leadership roles } \\
\hline Education (student or house staff) & $63 \%$ & $27 \%$ & $<0.0001$ \\
\hline Hospital administration & $21 \%$ & $10 \%$ & $<0.0001$ \\
\hline Quality improvement initiatives & $33 \%$ & $18 \%$ & 0.0005 \\
\hline
\end{tabular}

* Academic: hospitalists who reported a full-time or part-time academic appointment. Values given are the percent of hospitalists responding "yes."

${ }^{\dagger}$ Nonacademic: hospitalists who reported an adjunct or volunteer faculty position, or no academic appointment. Values given are the percent of hospitalists responding "yes."

* Only significant differences are presented $(P<0.05)$.

Abbreviations: ICU, intensive care unit; PICC, peripherally inserted central catheter.

they provide regular service for general pediatric inpatients (98\% versus $86 \%$; $P<0.0001$ ) as well as subspecialty inpatients $(27 \%$ versus $17 \% ; P=$ 0.044). Non-NACHRI pediatric hospitalist respondents were twice as likely to report the provision of regular service in the normal newborn nursery (49\% versus $22 \% ; P<0.0001$ ), the neonatal ICU 
(21\% versus $8 \%, P=0.002$ ), and the emergency department (38\% versus $20 \%$; $P<0.0001$ ).

Among respondents, pediatric hospitalists who were not working at a children's hospital were more likely to report that they sometimes or routinely performed lumbar punctures $(93 \%$ versus $85 \% ; P=0.037)$, infusion services $(36 \%$ versus $21 \% ; P=0.003$ ), and were twice as likely to perform circumcision ( $16 \%$ versus $8 \% ; P=0.041$ ) compared to those working at children's hospitals.

\section{Professional Roles and Parameters}

Respondents working in children's hospitals were twice as likely to hold a leadership position in utilization review ( $12 \%$ versus $6 \% ; P=0.012$ ), though respondents from non-NACHRI hospitals were more likely to at least participate in utilization review (58\% versus $40 \%$; $P=0.004$ ).

\section{Hospitalist Training}

Respondents from non-NACHRI hospitals were more likely to report that they had received no hospitalistspecific training $(68 \%$ versus $56 \% ; P=0.029$ ). Those at NACHRI hospitals were twice as likely to have received hospitalist training through a mentoring program $(20 \%$ versus $9 \% ; P=0.009)$.

\section{Freestanding versus Nonfreestanding Children's Hospitals Clinical Practice}

Pediatric hospitalist respondents employed at institutions that are not freestanding children's hospitals were more likely to report that they provided regular service in the normal newborn nursery ( $42 \%$ versus $14 \% ; P<0.0001$ ), pediatric ICU (22\% versus $5 \%$ ), emergency department (32\% versus $17 \% ; P<0.0001)$, and outpatient clinics $(23 \%$ versus $12 \% ; P=0.0068$ ). They were also more likely to perform or supervise sedation services (63\% versus $50 \% ; P=0.0116$ ), infusion services (32\% versus $17 \% ; P=0.0006$ ), PICC insertions (19\% versus $6 \% ; P=0.0002$ ), central line insertions (23\% versus $11 \%$; $P=0.0024$ ), and circumcisions $(16 \%$ versus $3 \% ; P<0.0001)$.

\section{Professional Roles and Parameters}

Among respondents, pediatric hospitalists employed by nonfreestanding children's hospitals were more likely to report participation in utilization review (51\% versus $38 \%$; $P=0.02$ ).

\section{Hospital Size Clinical Practice}

Pediatric hospitalist respondents working at large hospitals were twice as likely to report that they regularly provided service in the pediatric ICU (18\% versus $7 \% ; P=0.0072$ ) and were more likely to regularly perform circumcisions ( $13 \%$ versus 5\%; $P=0.0069$ ). Respondents from small hospitals were more likely to provide regular service in the neonatal ICU $(20 \%$ versus $7 \% ; P=0.0013)$.

\section{COTH Status: Teaching versus Nonteaching Hospitals Clinical Practice}

Among survey respondents, pediatric hospitalists employed by COTH hospitals were more likely to provide regular service in the neonatal ICU, compared to their peers in nonteaching hospitals $(15 \%$ versus $6 \% ; P=0.0109$ ). Those employed by nonCOTH hospitals were more likely to provide service in subspecialty inpatient service (38\% versus $16 \% ; P<0.0001)$, transports $(14 \%$ versus $6 \%$; $P=0.0227)$, inpatient consultation $(61 \%$ versus $45 \% ; P=0.0086)$, and the emergency response team (29\% versus $19 \%$; $P=0.0021)$.

\section{Professional Roles and Parameters}

Respondents from COTH hospitals were more likely to have no involvement in utilization review, compared to their peers at non-COTH hospitals ( $49 \%$ versus $37 \% ; P=0.0220$ ).

\section{DISCUSSION}

This study provides the most comprehensive information available regarding the clinical and nonclinical roles, training, work expectations, and career plans of pediatric hospitalists. Among the most important of our findings is the distribution of the length of time that pediatric hospitalists had served in their roles. While over one-third (37\%) reported having been practicing as hospitalists for over 5 years, $45 \%$ of our respondents had been in practice for fewer than 3 years. This is consistent with both the perceptions of rapid growth of the field and with significant turnover of hospitalists. ${ }^{1,8}$ It is important to note that our findings may actually overestimate the proportion of hospitalists with longer durations of employment as our sampling strategy would have been less likely to include those who left the field within the first 12 to 18 months of practice. Nevertheless, over half $(61 \%)$ of our respondents 
expected to remain a hospitalist for the duration of their career and few reported choosing to become a hospitalist as a short-term employment option. This finding has important implications for the future stability of the hospitalist workforce and the potential development of specific expertise among this cadre of clinicians. ${ }^{6}$

The demographic profile of pediatric hospitalists was also consistent with these findings. The mean age of 39 years for our respondents is indicative of a significant proportion of this group of physicians recently having completed their residency training. Further, the gender distribution approximates that of current pediatric residency graduates, thus indicating that that this is not a clinical choice for which there would be a skewed distribution as is the case in some pediatric subspecialties. $^{9}$

Our findings were similar to the 2004 Ottolini et al. ${ }^{10}$ findings on the roles of pediatric hospitalists. Respondents in our study reported spending less time providing inpatient care $(61 \%$ versus $75 \%$ ), providing clinical teaching or supervising residents ( $16 \%$ versus $26 \%$ ), performing administrative duties (8\% versus 19\%), and conducting research (3\% versus 9\%) compared with the respondents in the Ottolini et al. ${ }^{10}$ survey.

At this point in time, fewer than half of our respondents reported any hospitalist-specific training, including workshops at professional meetings or CME coursework. As there are a paucity of fellowships offering postresidency training in pediatric hospital medicine, and most of the existing programs are newly established, few in practice have completed such programs. ${ }^{11}$ In addition, most respondents reported that current CME offerings do not meet their needs, and that they could have used additional QI training to prepare them for their role as pediatric hospitalists. However, almost three-quarters of respondents (73\%) do not believe any additional training beyond residency should be required. As such, it is unclear if a defined, unique body of knowledge specific to hospitalists is either needed or desired by those currently in the field.

Although there are a broad range of potential clinical roles within hospital medicine, and this clinical variety influenced most respondents' decisions to become hospitalists, the current scope of an individual hospitalist tends to become somewhat focused. ${ }^{12,13}$ While we found almost all provided service on the pediatric inpatient unit, many fewer provided inpatient consultation and normal newborn care, or were involved in interhospital transport or as part of an emergency response team. There is also wide variation in the types of procedures performed or supervised by hospitalists at different institutions. More than half never perform or supervise infusion services, PICC or central line placement, or circumcision. The variation seen among hospitalists practicing in different hospital settings likely is a result, at least in part, of different needs in teaching hospitals for both service and for clinical experience of trainees. For example, our results demonstrate that pediatric hospitalists in nonteaching and non-children's hospitals are more likely to have a broader scope of clinical care provision. Another potential issue is that some hospitalists may be employed by institutions which have no pediatric ICU, neonatal ICU, or other specialty unit. As such, these hospitalists would not have the opportunity to work in such settings.

Further, those without academic appointments are also more likely to have expanded clinical roles compared with their academic counterparts. This may be due to the fact that there is likely a greater number of subspecialty-trained pediatric providers in academic centers and thus the need for hospitalists to cover specific services or perform specific procedures is lessened. There may also be a desire to prevent competition among care providers within the same institution. In contrast, hospitalists with academic appointments are more likely (though still uncommonly) to have taken leadership roles in hospital administration and QI initiatives. Thus, the nature of their efforts appears to expand into nonclinical delivery areas.

Clearly, hospitalists report they have assumed a significant role in the clinical teaching of trainees at all levels, with $94 \%$ of our respondents maintaining at least some involvement in education. On average, they spend $16 \%$ of their time in educational efforts. However, there are few data on the impact of their work in this area. ${ }^{5,13}$ Studies in pediatrics to date have been limited to a few institutions, ${ }^{3,5}$ and have not addressed the issue from the perspective of residency program directors or those who are in charge of inpatient curricula.

This study, like the majority of studies related to pediatric hospitalists, is hampered by the difficulty of identifying pediatric hospitalists. Rather than utilizing a hospital medicine membership 
list, which would be potentially biased by selfselection, we attempted to obtain a more representative sample through utilization of the AHA database.

\section{CONCLUSIONS}

Findings from this study provide an additional perspective regarding pediatric hospitalists to add to our previous study of hospitalist program directors. ${ }^{1}$ However, the field is currently a moving target. Our data demonstrate that there is significant flux in the hospitalist workforce, uncertainty regarding turnover, and variation in the roles of these professionals in their clinical and nonclinical work environment. Moreover, additional studies of the educational impact of hospitalists on residency and medical student education are needed. Questions regarding the nature and degree of resident autonomy and experience conducting procedures in the hospitalist environment have been raised. These must be assessed through studies of residency program directors, their expectations of residents, and the curricula they have developed.

As with any new phenomenon, it will take time to understand the impact of hospitalists in a variety of domains. Additional research will be helpful in following the development of this field and the manner in which it will interface with existing medical practice and educational programs.

Address for correspondence and reprint requests: Gary L. Freed, MD, MPH, University of Michigan, 300 North Ingalls Building 6E08, Ann Arbor, MI 48109-0456; Telephone: (734) 615-0616; Fax: (734) 764-2599; E-mail: gfreed@med.umich.edu

Received 2 November 2007; revision received 11 August 2008; accepted 23 October 2008.

\section{REFERENCES}

1. Freed GL, Brzoznowski KF, Neighbors K, Lakhani I; The Research Advisory Committee of the American Board of Pediatrics. Characteristics of the pediatric hospitalist workforce: its roles and work environment. Pediatrics. 2007;120: 33-39.

2. Wachter RM. The evolution of the hospitalist model in the United States. Med Clin North Am. 2002;86: 687-706.

3. Freed GL, Uren RL. Hospitalists in children's hospitals: what we know now and what we need to know. J Pediatr. 2006;148:296-299.

4. Flanders SA, Wachter RM. Hospitalists: the new model of inpatient medical care in the United States. Eur J Intern Med. 2003;14:65-70.

5. Landrigan CP, Muret-Wagstaff S, Chiang VW, Nigrin DJ, Goldman DA, Finklestein JA. Effect of a pediatric hospitalist system on housestaff education and experience. Arch Pediatr Adolesc Med. 2002;156:877-883.

6. Plauth WH, Pantilat SZ, Wachter RM, Fenton CL. Hospitalists' perceptions of their residency training needs: results of a national survey. Am J Med. 2001;111:247-254.

7. Srivastava R, Landrigan C, Gidwani P, Harary OH, MuretWagstaff S, Homer CJ. Pediatric hospitalists in Canada and the United States: a survey of pediatric academic department chairs. Ambul Pediatr. 2001;1:338-339.

8. Wachter RM. Hospitalists in the United States: mission accomplished or work in progress? N Engl J Med. 2004; 350:1935-1936.

9. Althouse LA, Stockman JA. Pediatric workforce: a look at general pediatrics data from the American Board of Pediatrics. J Pediatr. 2006;148:166-169.

10. Ottolini MC, Landrigan CP, Chiang VW, Stucky ER, PRIS survey: pediatric hospitalist roles and training needs [Abstr]. Pediatr Res. 2004;55:360A.

11. Ranji SR, Rosenman DJ, Amin AN, Kripalani S. Hospital medicine fellowships: works in progress. Am J Med. 2006;119:1.e1-1.e7.

12. O'Leary KJ, Liebovitz DM, Baker DW. How hospitalists spend their time: insights on efficiency and safety. $J$ Hosp Med. 2006;1:88-93.

13. Carlson DW, Fentzke KM, Dawson JG. Pediatric hospitalists fill varied roles in the care of newborns. Pediatr Ann. 2003;32:802-810. 